\title{
Increased proteasome activator 28 gamma (PA28Y) levels are unspecific but correlate with disease activity in rheumatoid arthritis
}

Melanie Gruner ${ }^{1,2}$, Anja Moncsek ${ }^{1,3}$, Stefan Rödiger ${ }^{1}$, Dagmar Kühnhardt ${ }^{4}$, Eugen Feist ${ }^{2^{*}}$ and Ralf Stohwasser ${ }^{1}$

\begin{abstract}
Background: PA28Y (also known as Ki, REG gamma, PMSE3), a member of the ubiquitin-and ATP-independent proteasome activator family 11S, has been proved to show proteasome-dependent and -independent effects on several proteins including tumor suppressor p53, cyclin-dependent kinase inhibitor p21 and steroid receptor co-activator 3 (SCR-3). Interestingly, PA28Y is overexpressed in pathological tissue of various cancers affecting e. g. breast, bowl and thyroids. Furthermore, anti-PA28Y autoantibodies have been linked to several autoimmune disorders. The aim of this study was to develop and evaluate a novel and sensitive PA28Y sandwich ELISA for the quantification of PA28y serum levels in patients with cancer and autoimmune diseases for diagnostic and prognostic purposes.
\end{abstract}

Methods: PA28Y-specific polyclonal antibodies and recombinant His-tagged PA28Y were purified and used to develop a sandwich ELISA for the detection of circulating PA28Y. With this new assay, PA28y serum levels of patients with various cancers, rheumatoid arthritis (RA), Sjögren's syndrome (SS), adult-onset Still's disease (AOSD) and different connective-tissue diseases (CTD) were compared with healthy control subjects. Anti-PA28Y autoantibodies were additionally confirmed using a newly developed microbead assay.

Results: The developed PA28Y sandwich ELISA showed a high specificity with a detection limit of $3 \mathrm{ng} / \mathrm{ml}$. A significant up-regulation of circulating PA28 $y$ was detected in the sera of patients with cancer, RA, SS and CTD. A significant correlation was observed dependent on age as well as anti-PA28Y autoantibody levels with circulating PA28Y protein levels. Furthermore, PA28y serum levels showed a correlation with disease activity in patients with RA under treatment with the T-cell directed biological compound abatacept according to disease activity score 28 (DAS28) and erythrocyte sedimentation rate (ESR).

Conclusion: The application of PA28y as a novel biomarker for diagnostic purposes of a specific disease is limited, since elevated levels were observed in different disorders. However, the correlation with disease activity in patients with RA suggests a prognostic value, which needs to be addressed by further studies. Therefore our results show that PA28Y is a useful marker which should be included in studies related to novel treatments, e.g. abatacept.

Keywords: Proteasome activator PA28y, 205 proteasome, Sandwich ELISA, Microbeads, Autoimmune disorders, Rheumatoid arthritis, Abatacept, Cancer

\footnotetext{
*Correspondence: eugen.feist@charite.de

2Department of Rheumatology and Clinical Immunology and

Autoinflammatory Reference Centre at Charité, Charité-Universitätsmedizin

Berlin, Charitéplatz 1, D-10117 Berlin, Germany

Full list of author information is available at the end of the article
} 


\section{Background}

The proteasome is a multicatalytic protein complex that is essential for the degradation of cytosolic and nuclear proteins. It regulates a number of cellular functions including cell cycle, transcription and antigen processing [1-3]. The barrel-like 20S core particle contains 28 subunits that are arranged in two outer heptameric $\alpha$-rings and two inner heptameric $\beta$-rings which contain the three proteolytic active sites - $\beta 1, \beta 2$ and $\beta 5$ exhibit caspase-like, trypsin-like and chymotrypsin-like cleavage preference, respectively [4]. Protein cleavage is highly regulated through controlled substrate entry. Thereby, an activation of latent $20 \mathrm{~S}$ proteasome by activators is necessary for protein degradation. Whereas polyubiquitinated proteins are degraded through the ATP-dependent $26 \mathrm{~S}$ proteasome formed by the 20S core and the $19 \mathrm{~S}$ proteasomal activator (PA700), the 11S regulators (PA28 $\alpha$, PA28 $\beta$ and PA28 $\gamma$ ) act in an ubiquitin- and ATP-independent manner [2].

The interferon- $\gamma$-inducible PA28 $\alpha$ and PA28 $\beta$ subunits form heteroheptamers mainly found in the cytosol and are involved in the production of MHC class I ligands [5]. The so called immunoproteasome including the interferon- $\gamma$-inducible $\beta 1 \mathrm{i}, \beta 2 \mathrm{i}$ and $\beta 5 \mathrm{i}$ catalytic subunits is known to generate peptides that are more likely to bind to MHC class I molecules. Thus, immunoproteasomes are more relevant for antigen processing and efficient pathogen combat [3]. Furthermore, proteasomes are reported to be involved in disease prevention due to their complex role in apoptosis and cell cycle. Degradation of pro-apoptotic proteins such as tumor suppressor p53 and cell cycle regulator p21 as well as cleavage of proteins like I $K B$ that leads to the activation of the anti-apoptotic transcription factor NF-kB, reflects the major importance of this enzyme complex [6]. A modified expression and/or activity of constitutive and inducible proteasomes have been reported in several malignant diseases and autoimmune disorders. In Sjögren's syndrome catalytic subunits are up regulated at the mRNA level while the $\beta 1 \mathrm{i}$ subunit is deficient in B lymphocytes leading to increased apoptosis resistance after proteasome inhibition $[7,8]$. Moreover, circulating proteasomes were measured in serum or plasma samples using ELISA technique demonstrating elevated levels in patients with systemic autoimmune diseases [9] and suggesting a role as an independent prognostic factor in multiple myeloma [10].

Furthermore, the proteasome activator PA28y (REGy, $\mathrm{Ki}, \mathrm{PSME3})$ that is not interferon- $\gamma$-inducible and whose homoheptamers are mainly found in the nucleus was previously regarded to be an activator for the degradation of short peptides [11]. However, former studies reported that PA28y stimulates also the proteasomal degradation of larger proteins like steroid receptor coactivator-3 (SRC-3/AIB1) [12], cyclin-dependent kinase inhibitor p21 [13,14], Hepatitis C virus core protein [15], ubiquitin ligase
Smad ubiquitination regulatory factor 1 (Smurf1) [16] and insulin transcription activator MAFA [17]. In addition proteasome-independent functions of PA28y were shown. The activator plays a key role in chromosomal stability during mitosis [18], in the organization of nuclear speckles [19] and during the interaction with nuclear localization protein p30 of Human T-lymphotropic virus type I (HTLV-1) to increase viral spread [20,21]. Beside these important roles in multiple biological pathways including cell growth and cell cycle regulation, PA28y is also a mediator of apoptosis. Mdm2-dependent p53 degradation is enhanced by PA28y acting as a co-activator [22] and p53 activity is regulated through its cellular localization mediated by PA28y [23]. Due to these functions it seems to be very likely that PA28y is involved in carcinogenesis. Many studies revealed that PA28y is overexpressed in different tumor tissues and serum samples of patients with diverse cancers affecting colon [24,25], breast [26], larynx [27], lung [28], liver [29] and thyroids [30]. Thus, PA28y interferes with cell cycle, proliferation and invasion in poorly differentiated thyroid carcinoma cells [31]. Interestingly, PA28 $\gamma$ was first identified as the Ki-antigen target of autoantibodies in patients with systemic lupus erythematosus (SLE) [32]. Several subsequent investigators confirmed the detection of PA28y as an autoantigen in patients with SLE and correlated this antibody response to clinical and serological features including disease activity [33,34]. These studies demonstrate that there is an urgent need for a rapid and simple robust routine diagnostic test to quantify the serum levels of PA28y. However, most studies so far have been performed from tissue which is laborious and not quantitative und therefore not applicable for progression monitoring.

The aim of the present study was to develop and to evaluate a quantitative PA28y sandwich ELISA to clarify its significance for diagnosis and prognosis of different diseases. We suggest that this assay with PA28y as putative predictive marker is an excellent tool to investigate the complex of diseases (autoimmune and cancer) which are potentially related to alterations in levels of PA28y. Our first results indicate that PA28y levels can be reliably measured in serum samples from patients with various diseases like cancer, rheumatoid arthritis (RA) and other autoimmune as well as autoinflammatory disorders. Moreover, PA28y serum levels seem to correlate with disease activity in RA patients treated with T-cell inhibitor abatacept.

\section{Methods}

\section{Chemicals and reagents}

All chemicals and reagents used were obtained from Carl Roth (Karlsruhe, Germany), Thermo Fisher Scientific (Rockford, USA), Roche Diagnostics (Mannheim, Germany) or Biochrom (Berlin, Germany) unless otherwise stated. 


\section{Patients}

All sera were obtained at the Charité University Hospital Berlin, Germany after informed consent. Following patient groups were investigated: 28 patients with various tumors (cancer), 104 patients with rheumatoid arthritis (RA), 34 patients with Sjögren's syndrome (SS), 15 patients with adult-onset Still's disease (AOSD), 66 patients with different connective-tissue diseases including polymyositis (PM, $\mathrm{n}=18$ ), systemic lupus erythematosus (SLE, $\mathrm{n}=37$ ) and undifferentiated connective-tissue disease (UCTD, $\mathrm{n}=11$ ) and 20 healthy subjects. Cancer group includes patients with advanced metastatic tumors: 20 subjects with breast cancer, 4 subjects with colon carcinoma, 1 subject with parotis gland cancer, 1 subject with sarcoma, 1 subject with a neuroendocrine tumor and 1 subject with carcinoma of unknown primary. With the exception of 2 cases all cancer patients were under treatment with chemotherapy with or without immuno or hormone therapy.

To study follow-up samples in correlation to disease activity according to DAS28-ESR (disease activity score 28 - erythrocyte sedimentation rate) and CRP (C-reactive protein), 13 RA patients under abatacept were included and sera were obtained before initiation of treatment as well as at week 16 and 24. All RA patients failed respond to methotrexat (MTX) treatment and received abatacept as first-line biologic in combination with MTX.

The study was approved by the local ethic committee at the Charité-Universitätsmedizin Berlin.

\section{Recombinant antigen production}

To obtain protein for standard curve development for sandwich ELISA human PA28y cDNA was amplified by polymerase chain reaction (PCR) and cloned into pDest17 expression vector following Gateway Recombinant Cloning Technology (Life Technologies, Darmstadt, Germany). The construct was transformed into E. coli BL21(DE3)pLysS and after induction of expression with $2 \mathrm{mM}$ IPTG for $2 \mathrm{~h}$ at $30^{\circ} \mathrm{C}$ bacteria were harvested. Solubilization of precipitated His-tagged PA28y was performed following a modified method of Ahmed et al. [35]. Frozen pellets were thawed and lysed with lysis buffer (50 mM Tris/ $\mathrm{HCl} \mathrm{pH} \mathrm{8.0,} 50 \mathrm{mM} \mathrm{NaCl}, 1 \mathrm{mM}$ EDTA, complete protease inhibitor). After addition of $300 \mu \mathrm{g} / \mathrm{ml}$ lysozym and $1 \mathrm{mg} / \mathrm{ml}$ sodium deoxycholate the suspension was incubated for $30 \mathrm{~min}$ on ice and further $15 \mathrm{~min}$ at RT after addition of approximately $10 \mathrm{U} / \mathrm{ml}$ DNase I and $10 \mathrm{mM} \mathrm{MgCl}_{2}$. Insoluble components were pelleted during centrifugation at $17,000 \times \mathrm{g}$ for $15 \mathrm{~min}$ at $4^{\circ} \mathrm{C}$ and washed with lysis buffer containing $0.5 \%$ Triton-X100 for $10 \mathrm{~min}$ at RT. After further centrifugation the pellet was dissolved in lysis buffer containing $8 \mathrm{M}$ Urea for a minimum of $2 \mathrm{~h}$ at RT. The soluble protein fraction was dialyzed against $20 \mathrm{mM}$ sodium phosphate buffer $\mathrm{pH} 7.4$ and insoluble impurities were removed by centrifugation $(17,000 \times \mathrm{g}$,
15 min). Protein amount was calculated using Pierce BCA Protein Assay Kit and purity was controlled by SDS-PAGE (sodium dodecyl sulfat-polyacrylamid gel electrophoresis).

\section{Antibodies}

The mouse monoclonal antibody raised against amino acids 45-147 of PA28y of mouse origin was purchased from Santa Cruz Biotechnology (Santa Cruz, USA). Secondary Horse radish peroxidase conjugated goat-anti-rabbit IgG and Cy5-conjugated goat-anti-human IgG were purchased from Dianova (Hamburg, Germany).

For production of polyclonal antiserum directed against PA28 rabbits were immunized by multiple intradermal injections of a PA28y specific KLH-coupled peptide representing amino acids 14-28 with citrullinated arginine in amino acid position 6 and 8 (Biogenes, Berlin, Germany). The collected serum (K3946) was precipitated with $40 \%$ ammonium sulfate, centrifuged $30 \mathrm{~min}$ at $15,000 \times \mathrm{g}$ and resuspended pellet was dialyzed against $20 \mathrm{mM}$ sodium phosphate buffer $\mathrm{pH}$ 8.0. Clarified (centrifugation at 15,000 $\times$ g, $30 \mathrm{~min}$ ) extract was purified by Protein An affinity column previously equilibrated in the same buffer on Äkta FPLC system (GE Healthcare, Munich, Germany). IgG complexes were eluted with $100 \mathrm{mM}$ Glycin/ $\mathrm{HCl}$ $\mathrm{pH} 3.0$ and $\mathrm{pH}$ was shifted to 8.0 with $\mathrm{NaOH}$. To avoid precipitation an end concentration of $100 \mathrm{mM} \mathrm{NaCl}$ was adjusted and pooled IgG fraction was dialyzed against PBS buffer $\mathrm{pH}$ 7.4. To get peptide specific antibodies the extract was further purified with an Ultra Link (Thermo Fisher Scientific, Rockford, USA) column containing immobilized PA28y specific amino acid sequence 14-28 in non-citrullinated form. The chromatography was performed using PBS $\mathrm{pH} 7.4$ as running buffer and $100 \mathrm{mM}$ Glycin/HCl pH 3.0 as elution buffer. The $\mathrm{pH}$ of the eluted peptide specific polyclonal rabbit IgG (rb-pIgG) was shifted to $\mathrm{pH} 8.0$ with $\mathrm{NaOH}$ and an end concentration of $100 \mathrm{mM} \mathrm{NaCl}$ before dialysis against PBS $\mathrm{pH}$ 7.4. After clarifying by centrifugation $(17,000 \times \mathrm{g}, 15 \mathrm{~min})$ and protein concentration estimation by photospectrometrical measurement the pooled fractions were adjusted to $0.02 \% \mathrm{NaN}_{3}$ and stored in Aliquots at $-20^{\circ} \mathrm{C}$ with an end concentration of $500 \mu \mathrm{g} / \mathrm{ml}$.

\section{Immunoblotting}

For immunoblotting, $30 \mu \mathrm{g}$ total cell extract of a human

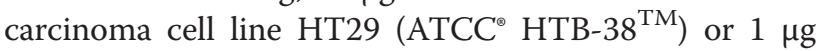
purified recombinant His-PA28 $\gamma$ were separated by SDS-PAGE and transferred onto PVDF membranes. Remaining binding sites were blocked with $5 \%$ nonfat dry milk in PBS buffer pH 7.4 containing 0.1\% Tween-20 (PBST) for $1 \mathrm{~h}$. Membranes were incubated with crude rabbit hyperimmunserum raised against PA28 $\gamma$-peptide (1:5,000), eluted fraction of protein A purification step $(1: 2,500)$ or rb-pIgG $(1: 2,500)$ in PBST for $1 \mathrm{~h}$. Then 
secondary goat-anti-rabbit IgG antibody coupled with horseradish peroxidase $(1: 10,000)$ was added for $1 \mathrm{~h}$. Antibody binding was visualized using ECL solution and released chemiluminescence was detected by using Lumi-Imager F1 (Roche Diagnostics, Mannheim, Germany).

\section{Sandwich ELISA for quantification of PA28 $\gamma$ in human sera}

To quantify the PA28y amount in human sera an indirect sandwich ELISA was developed. Nunc Polysorp microtiter plates were coated with $100 \mu \mathrm{l}$ of mouse monoclonal capture antibody diluted 1:500 in $100 \mathrm{mM}$ sodium carbonate buffer pH 9.6 overnight at $4^{\circ} \mathrm{C}$. Unbound material was removed with PBST buffer (PBS containing $0.1 \%$ Tween 20) and free binding sites were blocked with $300 \mu \mathrm{l} 1 \times$ Roti Block solution (Carl Roth, Karlsruhe, Germany) for $1 \mathrm{~h}$ at RT. After one further washing step $100 \mu \mathrm{l}$ of serum samples diluted 1:2 in PBST were added for $1 \mathrm{~h}$ following three washing steps. Wells were incubated with $100 \mu \mathrm{l}$ detection antibody rb-pIgG (1:250 in PBST) or PBST as negative control for $1 \mathrm{~h}$ before washing three times. After addition of $100 \mu \mathrm{l}$ of horseradish peroxidase (HRP)-conjugated secondary antibody diluted 1:5,000 and incubation for $1 \mathrm{~h}$, the microtiter plate was washed extensively with PBST buffer (three times). HRP activity was determined by adding $100 \mu \mathrm{l}$ tetramethylbenzidine substrate solution (Sigma-Aldrich, St. Louis, USA) following a $30 \mathrm{~min}$ incubation in the dark. Reaction was stopped with $100 \mu \mathrm{l}$ sulfuric acid stop solution (Sigma-Aldrich, St. Louis, USA) and absorbance was measured at $450 \mathrm{~nm}$ with a correction wavelength of $620 \mathrm{~nm}$ using the ELISA plate reader Synergy HT (Biotek, Bad Friedrichshall, Germany).

Recombinant His-PA28y in appropriate dilutions (3.125 to $200 \mathrm{ng} / \mathrm{ml}$ ) was used for calibration and the PA28y contents of human sera were calculated by subtracting negative control. The cutoff value was defined as the mean value plus 3 -fold standard deviation obtained from 20 healthy controls.

Reproducibility of sandwich ELISA was determined by intra- and inter-assay precision studies and calculated as the mean coefficient of variation $(\mathrm{CV})$. Therefore three sandwich assays with varying His-PA28y concentrations ranging from 0 to $200 \mathrm{ng} / \mathrm{ml}$ were performed on distinct plates at one day and reproduced on 3 different days.

\section{Microbead assay for determination of PA28 $\gamma$ autoantibody level}

Carboxylated poly(methyl methacrylate) microbeads (PolyAn GmbH, Berlin, Germany) were coupled with recombinant His-PA28y following MES buffer method [36]. The microbeads were immobilized on microtiter plates and incubated with human sera diluted 1:100. After addition of Cy5-conjugated secondary antibody the mean fluorescence intensity (MFI) of the microbeads was analyzed using VideoScan technology [37].

\section{Statistical analysis}

Statistical analyses were performed with IBM SPSS Statistic Version 21.0.0.0 and PKWard [38] using non-parametrical Mann-Whitney $U$ test to compare PA28 $\gamma$ levels in patient groups. The relationship between two variables was calculated using Pearson's correlation analysis. $P$ values less than 0.05 were considered to be statistically significant $\left({ }^{*}\right)$ and less than 0.01 were considered to be highly significant $\left({ }^{* * *}\right)$.

\section{Results}

Preparation of recombinant PA28 $\gamma$ and rabbit polyclonal antibodies to PA28y

To develop a PA28y sandwich ELISA for evaluating PA28y content in sera of patients with different diseases a standard protein for quantification was necessary. Therefore we expressed recombinant His-tagged PA28 $\gamma$ in E. coli BL21 and precipitated protein was extracted via a purification procedure containing a urea solubilization step. Figure 1A shows the different fractions during purification and the clear soluble His-PA28y protein that was used to generate the ELISA standard.

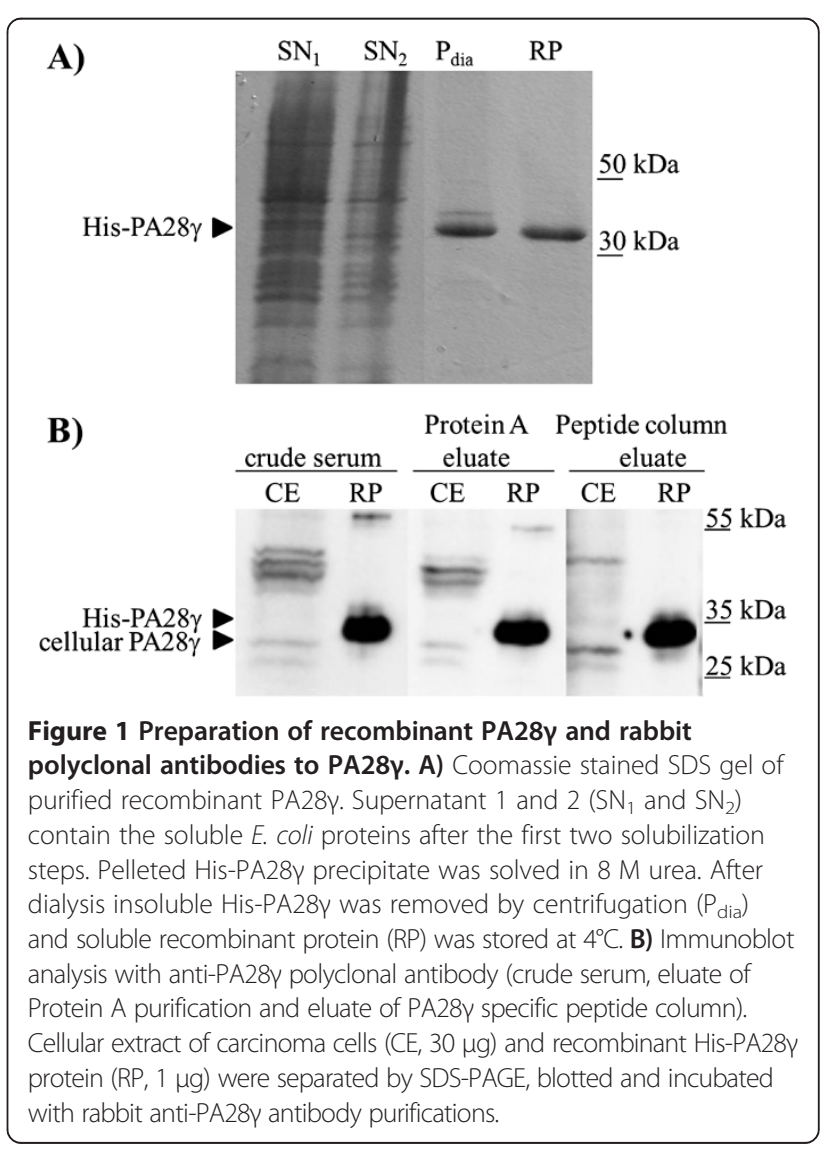


The immunization of a rabbit with the citrullinated PA28y-specific peptide revealed one polyclonal hyperimmunserum that formerly was thought to detect citrullinated antigens. Immunoblotting with recombinant un-citrullinated His-PA28y protein and cell lysates from human colon carcinoma cell line HT29 showed specific interaction of the serum with PA28y. To reduce background reactivity the serum was affinity purified using a protein A column. PA28 $\gamma$-specific IgG antibodies were enriched using an Ultra Link column containing the immobilized un-citrullinated peptide immunogen. The specificity of the purified PA28y antibodies was monitored by western blot analysis (Figure 1B). A $28 \mathrm{kDa}$ band corresponding to cellular PA28 $\gamma$ was detected by the rabbit antiserum in the cellular extract of the carcinoma cells, but there were also other bands corresponding to unspecific absorption or modified PA28y variants. The background reactivity was reduced by purification of polyclonal serum via protein $A$ and the peptide affinity purification steps. All antibody fractions that were collected during the antibody purification steps showed strong immunoreaction with recombinant His-PA28 $\gamma$ protein. Around $300 \mu \mathrm{g}$ of highly purified peptide specific polyclonal rabbit PA28 $\gamma$ antibody (rb-pIgG) could be obtained per $\mathrm{ml}$ of rabbit hyperimmunserum.

\section{Sandwich ELISA validation}

To validate the reproducibility of the sandwich ELISA the standard protein His-PA28 $\gamma$ was used in varying concentrations ranging from 0 to $200 \mathrm{ng} / \mathrm{ml}$. For intra-assay precision 3 microtiter plates coated with commercial monoclonal PA28y antibody were incubated with the His-PA28y solutions and antigen was quantified by using rb-pIgG in combination with a horseradish conjugated secondary anti-rabbit IgG antibody. The mean coefficient of variation (CV) ranged from $0.4 \%$ to $31.2 \%$ at day 1 , from $4.6 \%$ to $14.7 \%$ at day 2 and from $3.9 \%$ to $18.1 \%$ at day 3 (Table 1 ). Accordingly, the inter-assay CVs are represented by $10.9 \%$ to $18.1 \%$. The lower limit of PA28 $\gamma$ detection of the sandwich ELISA was found to be $3.125 \mathrm{ng} / \mathrm{ml}$ and

Table 1 Intra- and inter-assay precisions of PA28Y sandwich ELISA

\begin{tabular}{|c|c|c|c|c|c|c|c|c|}
\hline \multicolumn{9}{|c|}{ His-PA28y [ng/ml] } \\
\hline & 0 & 3.125 & 6.25 & 12.5 & 25 & 50 & 100 & 200 \\
\hline \multicolumn{9}{|c|}{ Intra-assay CV [\%], $\mathrm{n}=3$} \\
\hline day 1 & 0.4 & 10.4 & 16.7 & 31.2 & 19.9 & 9.3 & 16.8 & 10.4 \\
\hline day 2 & 8.7 & 14.7 & 7.6 & 4.6 & 13.8 & 7.9 & 4.9 & 5.2 \\
\hline day 3 & 18.1 & 4.9 & 7.0 & 16.5 & 3.9 & 6.5 & 9.1 & 10.9 \\
\hline \multicolumn{9}{|c|}{ Inter-assay CV [\%], $\mathrm{n}=\mathbf{3}$} \\
\hline day 1-3 & 10.9 & 10.9 & 10.9 & 18.1 & 15.8 & 11.9 & 14.6 & 13.1 \\
\hline
\end{tabular}

Precisions were calculated as the mean coefficient of variation (CV) of different PA28 $\gamma$ antigen concentrations measured with Sandwich ELISA in 3 independent experiments from duplicate wells at 3 days. the assay showed no reactivity with $11 \mathrm{~S}$ family members PA28 $\alpha$ or PA28 $\beta$ (data not shown).

\section{Circulating PA28y levels in human serum samples}

To determine the levels of circulating PA28 $\gamma$ in sera of patients with different diseases including cancer and autoimmune as well as autoinflammatory disorders a sandwich ELISA using two different PA28 $\gamma$-specific antibodies was implemented. The cutoff was calculated to be $39.8 \mathrm{ng}$ PA28y per $\mathrm{ml}$ of serum based on the measurement of twenty healthy donors. Summarized, 247 PA28 $\gamma$ serum levels from patients with various autoimmune or malignant diseases were measured and revealed significantly elevated results (median $=25.4 \mathrm{ng} / \mathrm{ml}, P=0.001$ ) compared with healthy controls (median $=18.1 \mathrm{ng} / \mathrm{ml}$, data not shown). In detail, in patients with Sjögren's syndrome (SS), a connective tissue disease affecting exocrine glands, $29.4 \%(10 / 34)$ were found to have significantly increased PA28y levels. Moreover, patients with other autoimmune diseases showed also increased PA28 $\gamma$ levels, in rheumatoid arthritis (RA) 26.9\% (28/104), in different connective-tissue diseases (CTD) 25.8\% (17/66) and in AOSD (adult-onset Still's disease) $13.3 \%$ (2/15). Of note, increased circulating PA28 $\gamma$ were only detected in $10.7 \%(3 / 28)$ of patients with different types of cancer (Figure $2 \mathrm{~A}$ ).

The frequency of different human PA28y serum levels is displayed in Figure 2B. Most sera showed a PA28y levels between 10 and $40 \mathrm{ng} / \mathrm{ml}$ and were therefore below the calculated cutoff. In up to $21 \%$ of patients with autoimmune diseases and cancer, increased PA28y levels between 40 and $100 \mathrm{ng} / \mathrm{ml}$ were measured. Of note, the highest PA28y concentrations over $100 \mathrm{ng} / \mathrm{ml}$ were observed in patients with SS, RA, CTD and cancer, with a maximum level of $637 \mathrm{ng} / \mathrm{ml}$.

The PA28 $\gamma$ levels of cancer patients $($ median $=246 \mathrm{ng} / \mathrm{ml}$; $P=0.003$ ), RA patients (median $=27.8 \mathrm{ng} / \mathrm{ml} ; P=0.0002$ ) and SS patients (median $=21.7 \mathrm{ng} / \mathrm{ml} ; P=0.008$ ) were significantly higher compared with the healthy control group $($ median $=18.1 \mathrm{mg} / \mathrm{ml})$. All cancer patients termed as PA28 $\gamma$ positive were diagnosed to advanced metastatic breast cancer. In contrast, patients with AOSD, an autoinflammatory disorder, showed no difference with respect to PA28y levels compared to healthy controls $\quad($ median $=19.7 \mathrm{ng} / \mathrm{ml} ; \quad P=0.142$ ). Patients with connective-tissue diseases (CTD) showed significantly increased PA28y levels compared with healthy controls (median $=23.0 \mathrm{ng} / \mathrm{ml} ; P=0.040)$. In detail, the SLE patient cohort expressed elevated PA28y protein levels in 9 of 37 cases but the levels were in total not significantly increased compared with healthy controls (median $=18.2 \mathrm{ng} / \mathrm{ml}$; $P=0.432$ ). With respect to PA28y serum levels patients with polymyositis (median $=24.5 \mathrm{ng} / \mathrm{ml} ; P=0.033$ ) and UCTD ( median $=30.9 \mathrm{ng} / \mathrm{ml} ; P=0.001$ ) differ in a significant way from healthy controls, respectively (Table 2 ). 


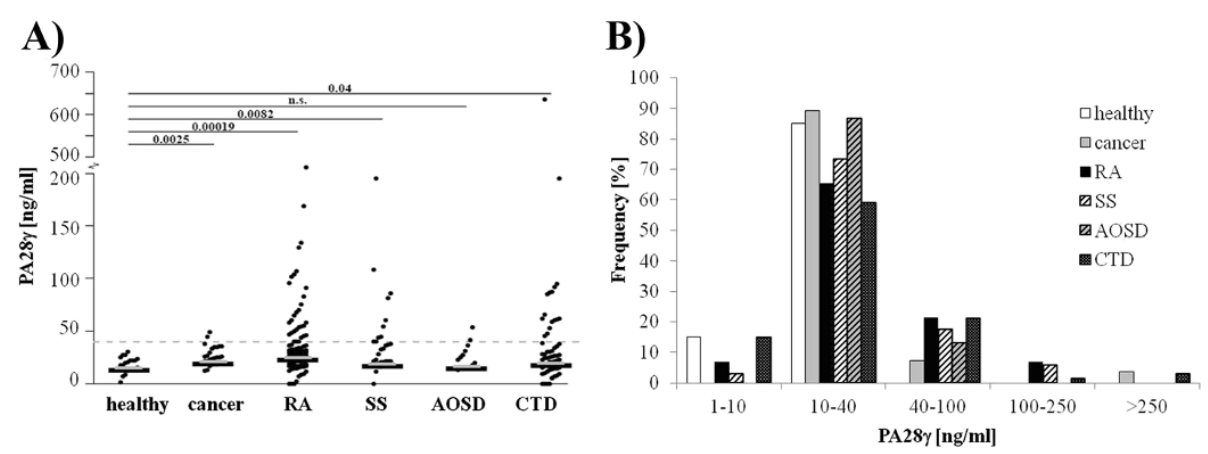

Figure 2 Circulating PA28 levels in human sera. A) Scatter dot plot of circulating PA28y serum levels measured by sandwich ELISA in patients with cancer $(n=28)$, rheumatoid arthritis (RA, $n=104)$, Sjögren's syndrome $(S S, n=34)$, adult onset Still's disease $(A O S D, n=15)$ and different connective-tissue diseases ( $C T D, n=66)$ compared with healthy controls $(n=20)$. Dashed line indicates the calculated cutoff value for positive response of $39.8 \mathrm{ng} / \mathrm{ml} \mathrm{PA28 \gamma}$ as the mean plus 3-fold standard deviation of healthy controls. The results are represented as mean PA28Y levels of duplicate wells. Medians are shown as grey lines. P-values as indicated compared with healthy control. n.S., not significant. B) Frequency of different PA28y serum levels in healthy and pathological subjects.

\section{Correlation of circulating PA28y levels with patients characteristics and disease activity in RA}

Of note, PA28y serum levels seems to be significant negative correlated with age in RA patients $(r=-0.223$; $P=0.032$ ). Furthermore, female RA subjects expressed significantly higher levels of PA28y $(P<0.001)$ compared with healthy controls, whereas male RA patients differed only marginally $(P=0.047)$. Overall, the difference between male and female RA patients was not significant $(P=0.170$, data not shown).

The parallel measurement of PA28 $\gamma$ protein levels by sandwich ELISA and anti-PA28y autoantibody titers by microbead assay in twelve patients with RA revealed a positive correlation $(\mathrm{r}=0.648 ; P=0.023)$ (data not shown).

To clarify whether circulating PA28 $\gamma$ is bound to intact $20 \mathrm{~S}$ proteasome complexes a highly specific polyclonal anti-20S rabbit serum was used instead of the polyclonal anti-PA28y detection antibody in the sandwich assay. Since no measurable signals were obtained, co-capturing could be excluded (data not shown).

The kinetic of PA28y serum levels was analyzed in follow-up samples of thirteen RA patients before and under treatment with abatacept after 16 and 24 weeks, respectively (Figure 3). In $61.5 \%(8 / 13)$ of cases the PA28y levels decreased in the first decade. However, the levels recovered in six of these eight patients after 24 weeks similar to the levels prior to treatment (Figure 3B). Abatacept is a fusion protein composed of the Fc region of IgG1 and the CTLA-4 extracellular domain. This biological compound inhibits the activation of T-cells and thus, has immunosuppressive effects. While proteasome activator family members PA28 $\alpha$ and PA28 $\beta$ are interferon- $\gamma$-inducible and involved in antigen presentation, the exact role of PA28 $\gamma$ is still unclear. Nevertheless, PA28y serum levels were compared with disease activity according to DAS28-ESR during

Table 2 Mean PA28y level (ng/ml), standard deviations (SD), minimum (min.) and maximum (max.) values from patients with different diseases

\begin{tabular}{|c|c|c|c|c|c|c|c|}
\hline Disease & $n$ & mean & SD & $\min$. & $\max$. & PA28y positive & $P$ value \\
\hline Healthy & 20 & 17.5 & 7.4 & 1.4 & 29.6 & $0.0 \%(0 / 20)$ & \\
\hline Cancer & 28 & 39.6 & 72.7 & 11.9 & 407.8 & $10.7 \%(3 / 28)$ & $* * 0.003$ \\
\hline RA & 104 & 37.6 & 33.5 & 0.0 & 205.8 & $26.9 \%(28 / 104)$ & **0.0002 \\
\hline SS & 34 & 37.1 & 36.1 & 0.0 & 195.2 & $29.4 \%(10 / 34)$ & ${ }^{* *} 0.008$ \\
\hline AOSD & 15 & 23.8 & 11.9 & 12.4 & 52.9 & $13.3 \%(2 / 15)$ & 0.142 \\
\hline \multicolumn{8}{|l|}{ CTD: } \\
\hline Polymyositis & 18 & 31.1 & 21.2 & 6.7 & 85.4 & $22.2 \%(4 / 18)$ & *0.033 \\
\hline SLE & 37 & 60.0 & 127.7 & 0.0 & 636.6 & $24.3 \%(9 / 37)$ & 0.432 \\
\hline UCTD & 11 & 35.9 & 15.4 & 18.4 & 61.7 & $36.4 \%(4 / 11)$ & ${ }^{* *} 0.001$ \\
\hline total CTD & 66 & 48.1 & 96.8 & 0.0 & 636.6 & $25.8 \%(17 / 66)$ & ${ }^{*} 0.040$ \\
\hline
\end{tabular}

Data over the calculated cutoff are defined as PA28 positive. $P$ values represent significance $\left({ }^{*}, P<0.05\right.$ and $\left.{ }^{* *}, P<0.01\right)$ compared with healthy control group. AOSD; adult-onset Still's disease, CTD; different connective-tissue diseases, RA; rheumatoid arthritis SLE; systemic lupus erythematosus, SS; Sjögren's syndrome, UCTD; undifferentiated connective-tissue disease. 


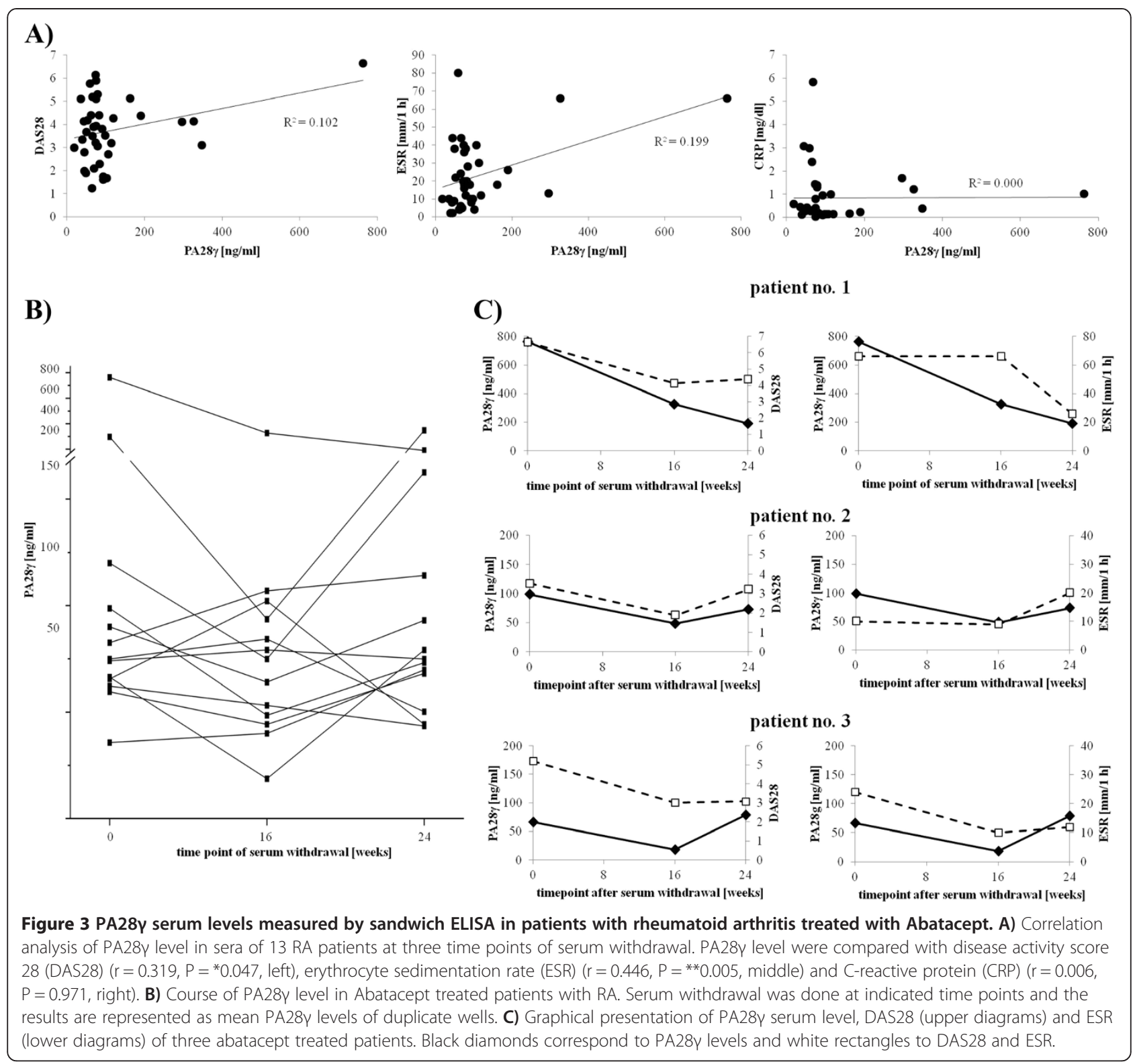

abatacept treatment. Of note, a significant correlation with disease activity $(\mathrm{r}=0.319, P=0.047)$ and ESR $(\mathrm{r}=0.446$, $P=0.005)$, but not with CRP levels under abatacept treatment was confirmed (Figure 3A). In fact, PA28y levels increased with disease activity and ESR values. Instructive cases over a follow-up period of 6 month are shown in Figure 3C.

\section{Discussion}

In the present study, an indirect sandwich ELISA for the quantification of the proteasome activator $28 \gamma$ was established. A mono-specific PA28y antibody recognizing $\mathrm{C}$ - and N-terminal regions of the peptide immunogen was purified from polyclonal rabbit serum via a PA28y peptide column. Recombinant His-PA28y was expressed in E. coli, purified and used as calibration protein. Optimal antibody compositions and dilutions were improved to develop an ELISA method with a sensitivity of $3 \mathrm{ng} / \mathrm{ml}$. To our best knowledge, we describe for the first time elevated PA28y levels both in sera from patients with different autoimmune and malignant disorders. We showed that the levels differed significantly from the healthy controls. The specificity of the test was confirmed by using recombinant PA28 $\alpha$ and PA28 $\beta$ proteins as antigens, which have up to $40 \%$ homology with PA28y [39], but were not detected by the assay.

Several studies suggested PA28 $\gamma$ as a novel biomarker in cancer diseases. Roessler et al. [24] detected PA28y in 
the circulation and demonstrated high levels of PA28y in serum samples from patients with colorectal cancer for the first time. They measured PA28y levels with an immunoassay analogical to a sandwich ELISA, but through time consuming preincubation of serum with biotinylated and digoxigenylated antibodies. Also Chen et al. [25] detected an overexpression of PA28y in tissue of patients with colorectal cancer. Wang et al. [26] indicated an overexpression of PA28 $\gamma$ in breast cancer and demonstrated a relation of expression with cancer status and metastasis. Kondo et al. [29] mentioned an increase of nuclear PA28y with the progression of liver disease from hepatitis $C$ virus related chronic hepatitis to liver cirrhosis. These findings suggest PA28y as target for prevention and/or treatment of hepatocellular carcinoma. Li et al. [27] suggested that PA28y overexpression in laryngeal cancer can promote proliferation and accelerate growth of cancer cells. He et al. [28] validated an overexpression of PA28 $\gamma$ in cancer tissue not only on protein level but also on gene level with significant correlation with cancer related genes suggesting a role of PA28 $\gamma$ in tumor development. These facts leads us to assume that PA28 $\gamma$ itself is not only overexpressed in cancer cells but is also detectable in the serum of patients with malignant diseases. In this context, the developed PA28y sandwich ELISA should clarify if elevated PA28y levels represent a useful biomarker to distinguish between different disorders or correlates with disease activity.

As a result, our data provided evidence that in healthy subjects the PA28y serum level is low and ranges from 1.4 to $29.6 \mathrm{ng} / \mathrm{ml}$. In general, a concentration of 10 to $40 \mathrm{ng} / \mathrm{ml} \mathrm{PA28 \gamma}$ was typical for the majority of all tested patient groups, while increased levels of PA28y were observed in only certain patients. In fact, nearly all investigated patient groups exhibit significant elevated levels of PA28 $\gamma$, specifically cancer, SS, PM and UCTD subjects. However, the highest PA28y levels were observed among patients with rheumatoid arthritis. Of note, AOSD and SLE patients showed no significant elevated PA28y serum levels compared to healthy controls. Taken together the results indicate that serum levels of PA28y alone are not useful for differentiation between malignant or systemic autoimmune disorders tested in this study. A qualification of PA28y serum levels as biomarker to distinguish between different cancers could not be excluded due to low random numbers. However, we were able to demonstrate a difference between healthy and ill subjects. In disease case the PA28y serum levels showed an average of $39.7+/-61.2 \mathrm{ng} / \mathrm{ml}$ which is markedly elevated compared with healthy controls $(17.5+/-7.4 \mathrm{ng} / \mathrm{ml})$. We claim that levels above $39.8 \mathrm{ng} / \mathrm{ml}$ can be used as qualitative marker to group patients.
Further, the high frequency of PA28y elevation in patients with RA was remarkable and was further analyzed in follow-up experiments with active RA before and after initiation of the T-cell directed therapy with abatacept. While PA28 $\alpha$ and PA28 $\beta$ are known to be induced by interferon- $\gamma$ and play a central role in antigen presentation, PA28y appears not to be majorly involved in immune defense. Surprisingly, a correlation of PA28y serum levels with DAS28 and ESR were shown. Thus, further studies in larger cohorts of RA patients are of interest to clarify the importance of PA28y as a new disease activity biomarker. Another interesting observation is the correlation of PA28y levels with age in RA patients with lower levels in elderly subjects. Recent studies demonstrated that the PA28y-proteasome system is involved in regulation of aging thru degradation of casein kinase 1 (CK1), which negatively regulates $\mathrm{Mdm} 2$. PA28y depletion in mice lead to p53 accumulation and induced premature aging [40]. The underlying biology of decreasing PA28y levels in aging RA patients remains unknown and requires further investigations.

In addition to the correlation analyses with well-known biomarkers, PA28y serum levels were compared with anti-PA28y autoantibody levels. These autoantibodies were detected in several autoimmune disorders including SLE and SS [41]. Our results indicate a significant

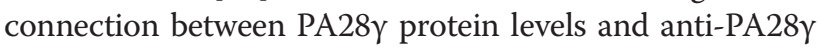
autoantibody levels even in RA sera. Circulating PA28y might exert a pro-inflammatory reaction leading B-cells to the production of misdirected autoantibodies.

It remains unknown, how PA28y is released into the circulation and whether this is related to increased apoptotic and necrotic cell turnover in patients with cancer and autoimmune disorders. Interestingly, circulating proteins, in particular circulating $20 \mathrm{~S}$ proteasomes, were also described in various malignant and autoimmune disorders $[9,42,43]$. In this context, a release of cellular $20 \mathrm{~S}$ proteasome into the serum could lead to the simultaneously passing of bound activator PA28y. However, our first results revealed no interaction of serological PA28y and 20S proteasome arguing for an independent release of $20 \mathrm{~S}$ proteasome and PA28 $\mathrm{\gamma}$ but needs further investigations.

\section{Conclusion}

In summary, our findings confirmed that high amounts of PA28y serum levels are detectable in certain diseases including cancer and autoimmune disorders. The useful potential of PA28 $\gamma$ as novel diagnostic biomarker is limited, due to low specificity. However, the shown correlation with disease activity in RA patients is of further interest. It should be addressed in future studies, whether PA28y is of prognostic value with relation to pathogenesis in RA. 


\section{Abbreviations}

AOSD: Adult-onset Still's disease; ATP: Adenosine triphosphate; BCA: Bicinchoninic acid; CK1: Casein kinase 1; CRP: C-reactive protein; CTD: Connective-tissue disease; CV: Coefficient of variation; DAS28: Disease activity score 28; ELISA: Enzyme linked immunosorbent assay; ESR: Erythrocyte sedimentation rate; HRP: Horseradish peroxidase; Mdm2: Mouse double minute 2 homolog; MHC: Major histocompatibility complex; mRNA: Messenger ribonucleic acid; PA28ץ: Proteasome activator 28 gamma; MTX: Methotrexat; NF-KB: Nuclear factor 'kappa-light-chain-enhancer' of activated B-cells; PBS: Phosphate buffered saline; PBST: Phosphate buffered saline plus Tween-20; PCR: Polymerase chain reaction; PM: Polymyositis; RA: Rheumatoid arthritis; rb-plgG: Peptide specific polyclonal rabbit lgG; RT: Room temperature; SCR-3: Steroid receptor co-activator 3; SDSPAGE: Sodium dodecyl sulfat-polyacrylamid gel electrophoresis; SLE: Systemic lupus erythematosus; SS: Sjögren's syndrome; UCTD: Undifferentiated connective-tissue disease.

\section{Competing interests}

EF received honoraria and grant support from BMS. All other authors declare that they have no competing interests.

\section{Authors' contributions}

MG contributed to the conception and design of the study, performed experiments and statistical analysis and wrote the manuscript. AM was involved in experimental bases. SR was involved in statistical analysis and data interpretation. DK picked out patients and provided cancer patient samples. EF contributed to the conception and supervision of the study, provided sera and helped to draft the manuscript. RS contributed to the conception and supervision of the study and helped to draft the manuscript. All authors read and approved the final manuscript.

\section{Acknowledgments}

We thank Attomol GmbH (Lipten, Germany) for providing microbeads and VideoScan technology as well as Dr. Thomas Häupl, his team and Silvia Pade (Charité-Universitätsmedizin Berlin, Germany) for entrusting healthy control sera. Thanks to Lorena Martinez-Gamboa and Khetam Ghannam for help in the laboratory.

This work was partially supported by Bundesministerium für Wirtschaft und Technologie/ Zentrales Innovationsprogramm Mittelstand (BMWT/ZIM; project number KF2088001M08) and the BMBF (Federal Ministry of Education and Research, Germany, InnoProfile-Transfer 03IP611X).

\section{Author details}

${ }^{1}$ Faculty of Natural Sciences, Brandenburg Technical University Cottbus Senftenberg, Großenhainer Str. 57, D-01968 Senftenberg, Germany. ${ }^{2}$ Department of Rheumatology and Clinical Immunology and Autoinflammatory Reference Centre at Charité, Charité-Universitätsmedizin Berlin, Charitéplatz 1, D-10117 Berlin, Germany. ${ }^{3}$ Department of Biochemistry, Charité-Universitätsmedizin Berlin, Charitéplatz 1, D-10117 Berlin, Germany. ${ }^{4}$ Department of Hematology and Oncology, Charité-Universitätsmedizin Berlin, Charitéplatz 1, D-10117 Berlin, Germany.

Received: 8 September 2014 Accepted: 28 November 2014 Published: 8 December 2014

\section{References}

1. Ciechanover A: The ubiquitin-proteasome pathway: on protein death and cell life. EMBO J 1998, 17:7151-7160.

2. Stadtmueller BM, Hill CP: Proteasome activators. Mol Cell 2011, 41:8-19.

3. Tanaka K, Mizushima T, Saeki Y: The proteasome: molecular machinery and pathophysiological roles. Biol Chem 2012, 393:217-234.

4. Finley D: Recognition and processing of ubiquitin-protein conjugates by the proteasome. Annu Rev Biochem 2009, 78:477-513.

5. Sijts EJAM, Kloetzel PM: The role of the proteasome in the generation of MHC class I ligands and immune responses. Cell Mol Life Sci 2011, 68:1491-1502.

6. Dahlmann B: Role of proteasomes in disease. BMC Biochem 2007, 8(Suppl 1):S3.

7. Krause S, Kuckelkorn U, Dörner T, Burmester G-R, Feist E, Kloetzel P-M: Immunoproteasome subunit LMP2 expression is deregulated in Sjogren's syndrome but not in other autoimmune disorders. Ann Rheum Dis 2006, 65:1021-1027.
8. Martinez-Gamboa L, Lesemann K, Kuckelkorn U, Scheffler S, Ghannam K, Hahne M, Gaber-Elsner T, Egerer K, Naumann L, Buttgereit F, Dörner T, Kloetzel PM, Burmester GR, Faustman DL, Feist E: Gene expression of catalytic proteasome subunits and resistance toward proteasome inhibition of $\mathrm{B}$ lymphocytes from patients with primary sjogren syndrome. J Rheumatol 2013, 40:663-673.

9. Egerer K, Kuckelkorn U, Rudolph PE, Rückert JC, Dörner T, Burmester G-R, Kloetzel P-M, Feist E: Circulating proteasomes are markers of cell damage and immunologic activity in autoimmune diseases. J Rheumatol 2002, 29:2045-2052.

10. Jakob C, Egerer K, Liebisch P, Türkmen S, Zavrski I, Kuckelkorn U, Heider U, Kaiser M, Fleissner C, Sterz J, Kleeberg L, Feist E, Burmester G-R, Kloetzel P-M, Sezer $O$ : Circulating proteasome levels are an independent prognostic factor for survival in multiple myeloma. Blood 2007, 109:2100-2105.

11. Mao I, Liu J, Li X, Luo H: REGgamma, a proteasome activator and beyond? Cell Mol Life Sci 2008, 65:3971-3980

12. Li X, Lonard DM, Jung SY, Malovannaya A, Feng Q, Qin J, Tsai SY, Tsai M-J, O'Malley BW: The SRC-3/AIB1 coactivator is degraded in a ubiquitin- and ATP-independent manner by the REGgamma proteasome. Cell 2006, 124:381-392.

13. Chen X, Barton LF, Chi Y, Clurman BE, Roberts JM: Ubiquitin-independent degradation of cell-cycle inhibitors by the REGgamma proteasome. Mol Cell 2007, 26:843-852.

14. Li X, Amazit L, Long W, Lonard DM, Monaco JJ, O'Malley BW: Ubiquitin- and ATP-independent proteolytic turnover of p21 by the REGgamma-proteasome pathway. Mol Cell 2007, 26:831-842.

15. Suzuki R, Moriishi K, Fukuda K, Shirakura M, Ishii K, Shoji I, Wakita T, Miyamura T, Matsuura Y, Suzuki T: Proteasomal turnover of hepatitis C virus core protein is regulated by two distinct mechanisms: a ubiquitin-dependent mechanism and a ubiquitin-independent but PA28gamma-dependent mechanism. J Virol 2009, 83:2389-2392.

16. Nie J, Wu M, Wang J, Xing G, He F, Zhang L: REGgamma proteasome mediates degradation of the ubiquitin ligase Smurf1. FEBS Lett 2010, 584:3021-3027.

17. Kanai K, Aramata S, Katakami S, Yasuda K, Kataoka K: Proteasome activator PA28y stimulates degradation of GSK3-phosphorylated insulin transcription activator MAFA. J Mol Endocrinol 2011, 47:119-127.

18. Zannini L, Lecis D, Buscemi G, Carlessi L, Gasparini P, Fontanella E, Lisanti S, Barton L, Delia D: REGgamma proteasome activator is involved in the maintenance of chromosomal stability. Cell Cycle Georget Tex 2008 7:504-512.

19. Baldin V, Militello M, Thomas Y, Doucet C, Fic W, Boireau S, Jariel-Encontre I, Piechaczyk M, Bertrand E, Tazi J, Coux O: A novel role for PA28gammaproteasome in nuclear speckle organization and SR protein trafficking. Mol Biol Cell 2008, 19:1706-1716.

20. Anupam R, Datta A, Kesic M, Green-Church K, Shkriabai N, Kvaratskhelia M, Lairmore MD: Human T-lymphotropic virus type 1 p30 interacts with REGgamma and modulates ATM (ataxia telangiectasia mutated) to promote cell survival. J Biol Chem 2011, 286:7661-7668.

21. Ko NL, Taylor JM, Bellon M, Bai XT, Shevtsov SP, Dundr M, Nicot C: PA28Y is a novel corepressor of HTLV-1 replication and controls viral latency. Blood 2013, 121:791-800.

22. Zhang Z, Zhang R: Proteasome activator PA28 gamma regulates $\mathrm{p} 53$ by enhancing its MDM2-mediated degradation. EMBO J 2008, 27:852-864.

23. Liu J, Yu G, Zhao Y, Zhao D, Wang Y, Wang L, Liu J, Li L, Zeng Y, Dang Y, Wang C, Gao G, Long W, Lonard DM, Qiao S, Tsai M-J, Zhang B, Luo H, Li X: REGgamma modulates p53 activity by regulating its cellular localization. J Cell Sci 2010, 123(Pt 23):4076-4084.

24. Roessler M, Rollinger W, Mantovani-Endl L, Hagmann M-L, Palme S, Berndt $P$, Engel AM, Pfeffer $M$, Karl J, Bodenmüller H, Rüschoff J, Henkel T, Rohr G, Rossol S, Rösch W, Langen H, Zolg W, Tacke M: Identification of PSME3 as a novel serum tumor marker for colorectal cancer by combining two-dimensional polyacrylamide gel electrophoresis with a strictly mass spectrometry-based approach for data analysis. Mol Cell Proteomics 2006, 5:2092-2101.

25. Chen D, Yang $X$, Huang L, Chi P: The expression and clinical significance of PA28 $\gamma$ in colorectal cancer. J Investig Med Off Publ Am Fed Clin Res 2013, 61:1192-1196

26. Wang X, Tu S, Tan J, Tian T, Ran L, Rodier J-F, Ren G: REG gamma: a potential marker in breast cancer and effect on cell cycle and proliferation of breast cancer cell. Med Oncol Northwood Lond Engl 2011, 28:31-41. 
27. Li L-P, Cheng W-B, Li H, Li W, Yang H, Wen D-H, Tang Y-D: Expression of proteasome activator REGy in human laryngeal carcinoma and associations with tumor suppressor proteins. Asian Pac J Cancer Prev 2012, 13:2699-2703.

28. He J, Cui L, Zeng Y, Wang G, Zhou P, Yang Y, Ji L, Zhao Y, Chen J, Wang Z, Shi T, Zhang P, Chen R, Li X: REGY is associated with multiple oncogenic pathways in human cancers. BMC Cancer 2012, 12:75.

29. Kondo M, Moriishi K, Wada H, Noda T, Marubashi S, Wakasa K, Matsuura Y, Doki Y, Mori M, Nagano H: Upregulation of nuclear PA28Y expression in cirrhosis and hepatocellular carcinoma. Exp Ther Med 2012, 3:379-385.

30. Okamura T, Taniguchi S-I, Ohkura T, Yoshida A, Shimizu H, Sakai M, Maeta H, Fukui H, Ueta Y, Hisatome I, Shigemasa C: Abnormally high expression of proteasome activator-gamma in thyroid neoplasm. J Clin Endocrinol Metab 2003, 88:1374-1383.

31. Zhang M, Gan L, Ren GS: REGy is a strong candidate for the regulation of cell cycle, proliferation and the invasion by poorly differentiated thyroid carcinoma cells. Braz J Med Biol Res Rev Bras Pesqui Médicas E Biológicas Soc Bras Biofísica Al 2012, 45:459-465.

32. Tojo T, Kaburaki J, Hayakawa M, Okamoto T, Tomii M, Homma M: Precipitating antibody to a soluble nuclear antigen "Ki" with specificity for systemic lupus erythematosus. Ryümachi Rheum 1981, 21(Suppl):129-140.

33. Yamanaka K, Takasaki Y, Nishida Y, Shimada K, Shibata M, Hashimoto H: Detection and quantification of anti-Ki antibodies by enzyme-linked immunosorbent assay using recombinant Ki antigen. Arthritis Rheum 1992, 35:667-671.

34. Cavazzana I, Franceschini F, Vassalini C, Danieli E, Quinzanini M, Airò P, Cattaneo R: Clinical and serological features of 35 patients with anti-Ki autoantibodies. Lupus 2005, 14:837-841.

35. Ahmed H: Principles and Reactions of Protein Extraction, Purification, and Characterization. Boca Raton: CRC Press; 2004.

36. Rödiger S, Ruhland M, Schmidt C, Schröder C, Grossmann K, Böhm A, Nitschke J, Berger I, Schimke I, Schierack P: Fluorescence dye adsorption assay to quantify carboxyl groups on the surface of poly(methyl methacrylate) microbeads. Anal Chem 2011, 83:3379-3385.

37. Rödiger S, Schierack P, Böhm A, Nitschke J, Berger I, Frömmel U, Schmidt C, Ruhland M, Schimke I, Roggenbuck D, Lehmann W, Schröder C: A highly versatile microscope imaging technology platform for the multiplex real-time detection of biomolecules and autoimmune antibodies. Adv Biochem Eng Biotechnol 2012, 133:35-74.

38. Rödiger S, Friedrichsmeier T, Kapat P, Michalke M: RKWard: a comprehensive graphical user interface and integrated development environment for statistical analysis with R. J Stat Softw 2012, 49:1-34

39. Kohda K, Ishibashi T, Shimbara N, Tanaka K, Matsuda Y, Kasahara M: Characterization of the mouse PA28 activator complex gene family: complete organizations of the three member genes and a physical map of the approximately $150-\mathrm{kb}$ region containing the alpha- and beta-subunit genes. I Immunol Baltim Md 1950 1998, 160:4923-4935.

40. Li L, Zhao D, Wei H, Yao L, Dang Y, Amjad A, Xu J, Liu J, Guo L, Li D, Li Z, Zuo D, Zhang Y, Liu J, Huang S, Jia C, Wang L, Wang Y, Xie Y, Luo J, Zhang B, Luo H, Donehower LA, Moses RE, Xiao J, O'Malley BW, Li X: REGy deficiency promotes premature aging via the casein kinase 1 pathway. Proc Natl Acad Sci 2013, 110:11005-10.

41. Matsushita M, Matsudaira R, Ikeda K, Nawata M, Tamura N, Takasaki Y: Anti-proteasome activator 28alpha is a novel anti-cytoplasmic antibody in patients with systemic lupus erythematosus and Sjögren's syndrome. Mod Rheumatol Jpn Rheum Assoc 2009, 19:622-628.

42. Feist E, Kuckelkorn U, Dörner T, Dönitz H, Scheffler S, Hiepe F, Kloetzel PM, Burmester GR: Autoantibodies in primary Sjögren's syndrome are directed against proteasomal subunits of the alpha and beta type. Arthritis Rheum 1999, 42:697-702.

43. Henry L, Lavabre-Bertrand T, Vercambre L, Ramos J, Carillo S, Guiraud I, Pouderoux P, Bismuth M, Valats J-C, Demattei C, Duny Y, Chaze I, Funakoshi N, Bureau JP, Daurès J-P, Blanc P: Plasma proteasome level is a reliable early marker of malignant transformation of liver cirrhosis. Gut 2009, 58:833-838.

doi:10.1186/1471-2474-15-414

Cite this article as: Gruner et al:: Increased proteasome activator 28 gamma (PA28Y) levels are unspecific but correlate with disease activity in rheumatoid arthritis. BMC Musculoskeletal Disorders 2014 15:414.

\section{Submit your next manuscript to BioMed Central and take full advantage of:}

- Convenient online submission

- Thorough peer review

- No space constraints or color figure charges

- Immediate publication on acceptance

- Inclusion in PubMed, CAS, Scopus and Google Scholar

- Research which is freely available for redistribution 